144 Siberian Journal of Economics and Management, Vol. 7, No 2, 2018

DOI: 10.12731/2070-7568-2018-2-144-166

УДК 332.146

\title{
ОЦЕНКА СОЦИАЛЬНО-ЭКОНОМИЧЕСКОЙ ПЕРСПЕКТИВНОСТИ ПРЕДПРИЯТИЙ СЕВЕРНЫХ РЕГИОНОВ РОССИИ
}

\author{
Жуков М.Н., Глоба С.Б.
}

Проведен анализ существующей методологии и инструментов мониторинга развития экономических систем. Рассмотрены особенности развития Северных регионов. Обоснована необходимость совершенствования системы мониторинга и управления развитием Северных регионов. Предложено применения критерия сочиальноэкономическая перспективность, разработаны методологические рекомендаџии и инструменты для его оценки. Проведен анализ отличий социально-экономической перспективности и инвестиционной привлекательности. Произведена оченка сочиально-экономической перспективности ПАО «НОВАТЭК».

Цель - совершенствование методологического аппарата мониторинга и управления развитием сочиильно-экономических систем Северных регионов.

Метод или методология проведения работы: в статье использовались экономико-математические, статистические, общенаучные методы анализа.

Результаты: разработаны рекомендации по совершенствованию методологического аппарата мониторинга и управления развитием сочиально-экономических систем Северных регионов. Установлена взаимосвязь экологической безопасности и инновачионной деятельности газодобывающих компаний.

Область применения результатов: полученные результаты иелесообразно применять в управлении предприятиями, инвесторам, органам государственной власти, региональным властям Северных территорий. 
Ключевые слова: социально-экономическая система; сочиильноэкономическая перспективность; инвестиционная привлекательность; кластер; человеческий капитал; инновации; конщепџия устойчивого развития; Северные регионы.

\section{ASSESSMENT OF SOCIO-ECONOMIC PROSPECTS OF ENTERPRISES IN THE NORTHERN REGIONS OF RUSSIA}

\section{Zhukov M.Y., Globa S.B.}

The analysis of the existing methodology and tools for monitoring the development of economic systems was made. Features of development of Northern regions are considered. The necessity of improving the system of monitoring and management of the development of the Northern regions is substantiated. It is proposed to apply the criterion of socio-economic prospects, developed methodological recommendations and tools for its evaluation. The analysis of differences between socio-economic prospects and investment attractiveness was made. The assessment of socio-economic prospects of PAO «NOVATEK» was made.

Purpose: Improvement of the methodological apparatus for monitoring and managing the development of social and economic systems in the Northern regions.

Methodology: in article economic-mathematical, statistical, general scientific methods of the analysis were used.

Results: recommendations on improvement of the methodological apparatus of monitoring and management of the development of socio-economic systems of the Northern regions are developed. The interrelation of ecological safety and innovative activity for the gas-producing companies is established.

Practical implications it is expedient to apply the received results the management of enterprises, investors, government authorities, regional authorities of the Northern territories.

Keywords: socio-economic system; socio-economic prospects; investment attractiveness; cluster; human capital; sustainable development concept; Northern regions. 


\section{Введение}

В контексте особенностей сложившейся на сегодняшний момент ситуации в эволюции мирового хозяйства вопросы совершенствования методологии мониторинга и управления развитием экономических систем приобретают особенную актуальность.

В настоящее время человеческая цивилизация проходит переломный этап своего развития. Это предопределяет количественное и качественное изменение параметров функционирования экономики. Подобные изменения снижают возможность применения упрощенных экономических моделей, разработанных на базе классических экономических школ. Наибольшую актуальность приобретают концепции и модели, учитывающие усложнение исследуемых систем, рост числа и качества взаимосвязей.

Проанализируем важнейшие тенденции текущего этапа развития современных социально-экономических систем. Основной массив значимых изменений в той или иной степени связан с повсеместным внедрением «индустрии 4.0» или четвертой технологической революции. Появление новых продуктов вызывает формирование новых рынков, изменение потребительской культуры, образа жизни. Происходит становление нового социального, духовного, интеллектуального типа человека, способного гибко адаптироваться к изменяющимся условиям жизни, эффективно оперировать непрерывно возрастающими объемами информационных потоков. Более того, потребителя активно воздействующего на рынок с целью изменения характеристик продукции и появления новых товаров, наиболее соответствующих его потребностям. Распространение подобных изменений потребительской культуры вызвало, в частности, повышение конкурентоспособности потребительски-ориентированных компаний, развитие краудфандинга, краудсорсинга и других форм интернализации клиентов и общественности [9]. В отечественных исследованиях среди ключевых проблем эффективного внедрения инноваций выделяется необходимость формирования институциональной среды [6]; учета поведенческих факторов [18]. Необходимость учета поведенческих факторов обосновывается ростом 
взаимосвязи технологического развития и образа жизни людей. Важность влияния технологий на человека подчеркивается многими зарубежными и отечественными исследователями. Уильям Митчел сформулировал понятие «электронный кочевник» [20]. Этот термин описывает образ жизни современного человека, широко использующего в профессиональной и частной жизни информационные технологии. Помимо преимуществ данная модель поведения порождает угрозы связанные с зависимостью от технических средств, беспомощностью при невозможности их использования; некритическим восприятием информации; отчужденностью в общении с окружающими. Алексеева И.Ю., Аршинов В.И., Чеклецов В.В. [1] рассматривают развитие технологий и рост их влияния на жизнь человека как продолжение эволюции, переход эволюционного процесса от биологической к «технобиологической» стадии.

Важнейшими следствиями распространения «индустрии 4.0», определяющими актуальность тематики проводимого исследования, являются рост роли малого инновационного бизнеса; распространение кластерной модели организации производства; рост производительности труда; автоматизация производства. Автоматизация производства приводит не только к сокращению потребности в трудовых ресурсах, но и к изменению структуры рынка труда [2]. Анализируя эту тенденцию в логистике В.И. Плещенко [12] приходит к выводу о сокращении потребности в сотрудниках занятых рутинным, стандартизированным трудом и росте потребности в специалистах обладающих креативными, творческими компетенциями. И.Д. Котляров [9] отмечает повышение активности участия работников в деятельности компаний, распространение механизма экстернализации сотрудников, наделение их функциями предпринимателей.

Острота и значимость указанных проблем неоднородны для различных объектов. Особую актуальность они приобретают для регионов, предприятий и проектов, испытывающих затруднения в развитии в рамках существующих моделей хозяйствования, однако претендующих на ключевую роль в рамках новой парадигмы раз- 
вития. Данная тенденция распространяется и на регионы Крайнего Севера. В регионе сконцентрированы значительные запасы минерального сырья. Сложность ведения хозяйственной деятельности в условиях Крайнего Севера, высокая уязвимость природной среды региона предопределяют необходимость использования прогрессивных технологических и организационных решений. Благодаря интенсификации прогресса в науке и технологиях, в том числе в области разведки, освоения и транспортировки природных ресурсов перспективы эффективного освоения региона и интерес к нему государств, международных организаций и корпораций в последние годы значительно возросли [8]. Северные регионы являются перспективной базой для международного сотрудничества в области ведения хозяйственной деятельности, судоходства, науки и образования. Особый интерес представляют междисциплинарные исследования в области устойчивого развития, вопросах изменения климата, испытаний новых приборов и материалов. Также в последние годы проводятся исследования в социальных науках, посвященные проблемам коренных народов Крайнего Севера.

Цель данной работы заключается в совершенствовании методологического аппарата мониторинга и управления развитием социально-экономических систем Северных регионов.

В теории эффективной организации производства большое значение имеют исследования в области инноваций, концепция устойчивого развития, кластерная модель. Тематике предпринимательства и инновационной деятельности посвящены исследования Й. Шумпетера, П. Друкера [17]. Большой вклад в теорию промышленных революций и концепции устойчивого развития внесли Д. Рифкин [22], К. Шваб [2]. Значимость соблюдения высоких экологических стандартов подтверждается зарубежными исследованиями. Многие фирмы в Европе используют практики экологического менеджмента, значительно превышающие законодательные требования и это положительно сказывается на финансовых результатах $[19,23]$. Исследования М. Портера имеют системообразующее значение в теории конкурентных преимуществ, 
оценке влияния окружения на конкурентоспособность, модели экономических кластеров [21].

Основными направлениями мониторинга состояния экономических систем в современном научном и бизнес сообществе являются оценка инвестиционной привлекательности, стоимости бизнеса, анализ финансового состояния, платежеспособности, ликвидности, финансовой устойчивости, экспертные методики, Форсайт [14].

Отечественная практика мониторинга развития экономических систем опирается на достижения западных исследователей, развивает их и адаптирует к российской специфике. Следует отметить работы А.Д. Шеремета [16], Г.В. Савицкой [13], Д.А Ендовицкого $[3,4]$, М.Н. Крейниной [10], оказавшие определяющее влияние на практику анализа хозяйственной деятельности и оценки инвестиционной привлекательности в России. Ключевая роль в данных методиках отводится комплексному анализу финансового состояния предприятия. Финансовое состояние определяется использованием финансовых ресурсов и получением финансовых результатов. Основной информационной базой для данных методик служит бухгалтерская отчетность. В методиках используются вертикальный, горизонтальный, факторный и коэффициентный анализ. Г.В. Савицкая [13] выделяет следующие составляющие финансового состояния: финансовая независимость, риск банкротства, кредитоспособность, платежеспособность. А.Д. Шеремет [16] придает особое значение структуре активов и пассивов, наличию собственных оборотных средств, соответствию уровня запасов нормативным величинам. Наиболее важными характеристиками финансового состояния, выделяемыми М.Н. Крейниной [10], являются соотношение собственных и заемных средств и обеспеченность собственными средствами. Разработке инструментария анализа и управления инвестиционной деятельностью посвящены работы Д.А Ендовицкого. В частности, сформулированы рекомендации по учету рисков, возникающих при реализации инвестиционных проектов, проанализирована взаимосвязь между инвестиционной привлекательностью и финансовыми показателями компании [3]. 


\section{Материалы и методы}

В большинстве существующих методик оценки инвестиционной привлекательности под целью подразумевается максимизация финансового результата. В соответствии с этим тезисом, нередко методика строится как оптимизация экономической модели по данному параметру. При этом недостаточно внимания зачастую уделяется обоснованию временного горизонта анализа. Учет данного фактора имеет большое значение, поскольку мероприятия, направленные на максимизацию текущего финансового результата, могут оказывать негативное влияние в долгосрочной перспективе. Актуальность отмеченного недостатка определяется тем, что в практической деятельности, максимизируя текущие показатели, и тем самым повышая инвестиционную привлекательность, менеджмент предприятия зачастую пренебрегает задачами устойчивого долгосрочного развития.

Необходимым условием реализации стратегии развития Российской Федерации является сглаживание противоречий между критериями общеупотребительных рыночных методик инвестиционного анализа и задачами сбалансированного развития страны. Реализация данного тезиса позволит повысить эффективность взаимодействия между государством и бизнесом, сориентирует частных инвесторов на перераспределение ресурсов в направлениях коррелирующих с государственной промышленной и региональной политикой.

По нашему мнению, на современном этапе для успешного развития регионов Крайнего Севера, национальных инновационных предприятий и других критически важных направлений российской экономики применение сложившейся концепции инвестиционной привлекательности является недостаточным и требует доработки. В связи с этим, в результате модернизации критерия инвестиционная привлекательность нами был разработан критерий социальноэкономическая перспективность.

Выделим основные отличия социально-экономической перспективности от инвестиционной привлекательности, которые предопределили необходимость разграничения этих понятий (табл. 1). 
Таблицуа 1.

Сравнительный анализ социально-экономической перспективности и инвестиционной привлекательности

\begin{tabular}{|c|c|c|c|}
\hline № & Признак & $\begin{array}{c}\text { Инвестиционная } \\
\text { привлекательность }\end{array}$ & $\begin{array}{c}\text { Социально-экономическая } \\
\text { перспективность }\end{array}$ \\
\hline 1. & $\begin{array}{c}\text { Взаимосвязь } \\
\text { с инвестици- } \\
\text { онной актив- } \\
\text { ностью } \\
\end{array}$ & $\begin{array}{c}\text { Является факторным призна- } \\
\text { ком по отношению к резуль- } \\
\text { тирующему признаку инве- } \\
\text { стиционная активность. }\end{array}$ & $\begin{array}{c}\text { Не всегда имеет высокую корреляци- } \\
\text { онную взаимосвязь с инвестицион- } \\
\text { ной активностью. }\end{array}$ \\
\hline 2. & $\begin{array}{c}\text { Возможность } \\
\text { получения } \\
\text { объективной } \\
\text { оценки } \\
\end{array}$ & $\begin{array}{c}\text { Теоретически существует, } \\
\text { но на практике труднодости- } \\
\text { жима. }\end{array}$ & $\begin{array}{c}\text { Более субъективна, чем инвестици- } \\
\text { онная привлекательность, поскольку } \\
\text { зависит от выбранных приоритетов } \\
\text { развития, баланса интересов и т.д. }\end{array}$ \\
\hline 3. & $\begin{array}{l}\text { Отражает ин- } \\
\text { тересы }\end{array}$ & $\begin{array}{c}\text { Инвесторы, собственники } \\
\text { (другие участники только } \\
\text { косвенно). }\end{array}$ & $\begin{array}{c}\text { Вся совокупность заинтересованных } \\
\text { субъектов; ориентируется, в первую } \\
\text { очередь, на оценку выполнения объ- } \\
\text { ектом его базовых функций. }\end{array}$ \\
\hline
\end{tabular}

Социально-экономическая перспективность - совокупность параметров объекта, позволяющая ему эффективно развиваться, адаптироваться к динамически изменяющимся условиям внешней среды на основе использования внутренних и внешних ресурсов и, посредством этого, устойчиво выполнять значимые функции в той экономической системе, к которой он относится.

Под используемыми ресурсами в данном определении в числе прочих подразумеваются и инвестиционные ресурсы. Функции экономического объекта могут заключаться в производстве качественной продукции, услуг; создании высокопроизводительных рабочих мест, обеспечении платежеспособного спроса на инвестиционные и кредитные ресурсы.

Социально-экономическая перспективность является авторской модификацией критерия инвестиционная привлекательность. Инвестиционная привлекательность и социально-экономическая перспективность тесно пересекаются между собой, могут численно оцениваться на основе идентичных методологических подходов. В определенных ситуациях числовая оценка социально-экономической перспективности может совпадать с инвестиционной привлекательностью.

При разработке методики оценки социально-экономической перспективности за основу была взята авторская методика оценки инвестиционной привлекательности [5]. 
Внесение изменений в состав показателей и математический аппарат основывалось на следующих принципах:

- простота использования методики для конечных пользователей;

- наглядность и удобство трактовки экономического смысла полученных значений;

- возможность адаптации методики к различным объектам оценки в зависимости от их индивидуальных особенностей;

- возможность использования методики при создании комплексной системы мониторинга в сочетании с другими инструментами анализа.

Интегральный показатель, оценивающий социально-экономическую перспективность, определяется как средневзвешенное значение общего и индивидуального компонентов. Оценка компонентов базируется на расчете системы показателей.

В группу для расчета общего компонента включаются стандартизированные показатели, которые могут быть определены для любого аналогичного объекта независимо от его индивидуальных особенностей. Численная оценка общего компонента может применяться для сравнения различных объектов.

Состав группы показателей для расчета индивидуального компонента определяется на основе особенностей исследуемого объекта.

На этапе разработки каждому показателю присваивается весовой коэффициент, определяющий его относительную значимость при расчете общего или индивидуального компонентов. Также для каждого показателя устанавливаются опорные значения: максимальное (Хмакс), минимальное (Хмин) и нормальное (Хнорм).

Смысловая нагрузка опорных значений и расчет оценки показателя зависят от того, как оцениваемый показатель влияет на социально-экономическую перспективность.

Назовем показатели, прямо пропорционально влияющие на социально-экономическую перспективность, позитивными. В качестве примера можно привести уровень доходов населения, прибыль.

Показатели, обратно пропорционально влияющие на социальноэкономическую перспективность, обозначим как негативные. Это 
могут быть уровень преступности, бедности, выбросы загрязняющих веществ.

За основу механизма вычисления оценок показателей был взят математический аппарат, разработанный для оценки инвестиционной привлекательности предприятий [5]. Для удобства отображения результатов, численные оценки показателей выражаются не в долях единицы, а в условных пунктах. Наилучшему состоянию объекта по конкретному показателю соответствует оценка «+1000», наихудшему - «-1000», нормальному или среднему по совокупности аналогичных объектов - «0».

Алгоритм расчета оценок показателей следующий: если значение показателя (Хф) больше максимального опорного значения - позитивным показателям присваивается оценка «+1000», негативным «-1000»; если показатель меньше минимального опорного значения - позитивным показателям присваивается оценка «-1000», негативным «+1000».

Если значение показателя находится между нормальным и максимальным опорным значением расчет оценки показателя $(\Phi)$ по модулю производится по формуле (1).

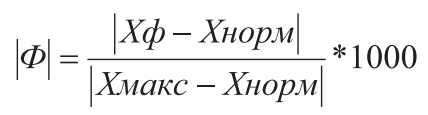

При этом оценке позитивных показателей присваивается знак «+», а негативных «-».

Если значение показателя находится между нормальным и минимальным опорным значением расчет оценки показателя по модулю производится по формуле (2).

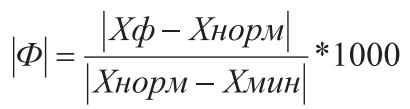

При этом оценке позитивных показателей присваивается знак «-», а негативных «+»».

Оценки общего и индивидуального компонентов определяются как средневзвешенное значение составляющих их показателей. 
Состав показателей и весовые коэффициенты общего компонента были подобраны на основе методики оценки инвестиционной привлекательности [5]. При этом, в соответствии с приведенными выше принципами, количество показателей было сокращено до пяти.

\section{Результаты и обсуждение}

Территории Арктики и Крайнего Севера имеют большое значение для развития нашей страны в силу значительного природноресурсного потенциала, необходимости обеспечения национальной безопасности, наличия уникальных условий для туристко-рекреационной деятельности, в том числе этно-туризма.

При этом необходимо учитывать ряд особенностей сдерживающих развитие данных регионов и требующих особых подходов при их освоении. Данные проблемы определяются, в первую очередь, географическим положением и климатическими условиями.

С нашей точки зрения, необходимо выделить ряд факторов являющихся ключевыми для формирования стратегии развития Крайнего Севера и отличающих её от стратегий других регионов: человеческий капитал; транспорт, логистика; экология; технологии, инновации.

Природная среда Крайнего Севера характеризуется высокой уязвимостью и низкой способностью к самовосстановлению. При этом основу экономической системы региона составляет ресурсодобывающий комплекс, имеющий высокую техногенную нагрузку на экологию. Решение утилизации отходов за пределами региона является проблематичным в силу высоких транспортных расходов. Кроме того, проблема осложняется значительным количеством накопленных отходов. Оптимальным решением представляется минимизация промышленных и бытовых отходов в рамках реализации концепции устойчивого природопользования в наиболее жесткой форме. Данный тезис требует применения инновационных технологических решений, как в области организации производства, так и в жилищно-коммунальном хозяйстве. Целесообразным является применение передового опыта развитых стран Северной Америки, 
Японии, Западной Европы. В частности, при осуществлении северного завоза должен производиться анализ продукции с точки зрения её утилизационных характеристик, применение инновационных видов упаковочных материалов и прочее.

Особенности Крайнего Севера, связанные с человеческим капиталом, также во многом определяются суровыми климатическими условиями. Необходимость создания комфортных условий для жизни и работы в условиях Крайнего Севера предопределяет актуальность проблем строительства жилья и объектов социальной инфраструктуры. Строительство в условиях Крайнего Севера требует применения инновационных технологий и материалов, обеспечивающих высокие характеристики по энергоэффективности и теплосбережению в местных климатических условиях. Текущее состояние объектов жилого фонда российских регионов Крайнего Севера характеризуется множеством накопленных проблем. Особенно остро проблема изношенности жилья стоит в поселках, местах проживания коренного населения [7]. Высокий уровень заработной платы в регионе объясняется необходимостью компенсации за неблагоприятные условия труда, а также высоким уровнем цен, связанным со значительными транспортными издержками. Высокая стоимость трудовых ресурсов предопределяет актуальность создания высокопроизводительных рабочих мест, применения инновационных технологий, автоматизации производства. Также, в связи с дороговизной трудовых ресурсов, в регионах Крайнего Севера нецелесообразно размещение обрабатывающих и вспомогательных производств.

Дороговизна организации производства на территории региона вызывает необходимость доставки из вне. Транспортно-логистическая система снабжения регионов Крайнего Севера имеет довольно сложную схему. Это связано с природными и географическими условиями, отдаленностью регионов. Транспортное снабжение региона характеризуется высокой стоимостью и зависимостью от сезона. Большое значение в транспортной схеме Арктических регионов играет Северный морской путь. 
Решение проблем развития регионов Крайнего Севера требует применения уникальных технологических решений, зачастую не имеющих мировых аналогов. Эта потребность стимулирует отечественные инновационные предприятия в строительной индустрии, машиностроении, судостроении и других отраслях.

В качестве примера числовой оценки социально-экономической перспективности приведем оценку компании «НОВАТЭК». Оценка производилась на основе публичной финансовой отчетности и иных сведений, размещенных на сайте компании и других открытых источниках [11].

Основной регион ведения деятельности ПАО «НОВАТЭК» Ямало-Ненецкий автономный округ находится на Крайнем Севере. Ямало-Ненецкий автономный округ занимает лидирующие позиции в мире по добыче и объёму запасов газа. Доля региона составляет $50 \%$ российской и $15 \%$ мировой газодобычи.

В таблице 2 приведены опорные показатели и весовые коэффициенты для расчета общего компонента. Все показатели, кроме коэффициента финансовой зависимости, являются позитивными, расчет показателей производится по общепринятым формулам [10, $13,16]$. Подбор опорных показателей базируется на теоретических рекомендациях $[10,13,16]$ и анализе статистической информации по ведущим российским компаниям [5].

Таблица 2.

Опорные значения и веса показателей общего компонента

\begin{tabular}{|c|l|c|c|c|c|}
\hline № & \multicolumn{1}{|c|}{ Показатель } & $\begin{array}{c}\text { вес, } \\
\text { доли ед. }\end{array}$ & Хмин & Хнорм & Хмакс \\
\hline 1. & Рентабельность продаж, \% & 0,16 & 0 & 25 & 60 \\
\hline 2. & Рентабельность активов, \% & 0,17 & 0 & 10 & 30 \\
\hline 3. & Рентабельность собственного капитала, \% & 0,17 & 0 & 17 & 50 \\
\hline 4. & Коэффициент абсолютной ликвидности & 0,2 & 0,05 & 0,2 & 0,5 \\
\hline 5. & Коэффициент финансовой зависимости & 0,3 & 0,35 & 0,6 & 0,8 \\
\hline
\end{tabular}

С помощью опорных показателей и весовых коэффициентов (табл. 2) произведем расчет оценок отобранных показателей компании и общего компонента (табл. 3$)$ по формулам $(1,2)$. 
Таблица 3.

Оценка показателей общего компонента

\begin{tabular}{|c|c|c|c|c|c|c|c|}
\hline № & \multicolumn{2}{|l|}{ Показатель } & 2013 & 2014 & 2015 & 2016 & 2017 \\
\hline 1. & \multirow{2}{*}{ Рентабельность продаж } & $\%$ & 48,27 & 35,72 & 29,61 & 41,91 & 28,08 \\
\hline 2. & & оценка & 665 & 306 & 132 & 483 & 88 \\
\hline 3. & \multirow{2}{*}{ Рентабельность активов } & $\%$ & 20,72 & 5,69 & 9,39 & 28,75 & 16,58 \\
\hline 4. & & оценка & 536 & -431 & -61 & 938 & 329 \\
\hline 5. & \multirow{2}{*}{$\begin{array}{l}\text { Рентабельность собственного } \\
\text { капитала }\end{array}$} & $\%$ & 33,10 & 9,71 & 18,18 & 48,82 & 23,23 \\
\hline 6. & & оценка & 488 & -429 & 36 & 964 & 189 \\
\hline 7. & \multirow{2}{*}{$\begin{array}{l}\text { Коэффициент абсолютной } \\
\text { ликвидности }\end{array}$} & $\begin{array}{c}\text { доли } \\
\text { ед. }\end{array}$ & 0,229 & 0,423 & 0,281 & 0,278 & 0,593 \\
\hline 8. & & оценка & 96 & 745 & 270 & 261 & 1000 \\
\hline 9. & \multirow{2}{*}{$\begin{array}{l}\text { Коэффициент финансовой } \\
\text { зависимости }\end{array}$} & $\begin{array}{c}\text { доли } \\
\text { ед. }\end{array}$ & 0,374 & 0,414 & 0,484 & 0,411 & 0,286 \\
\hline 10. & & оценка & 904 & 744 & 465 & 756 & 1000 \\
\hline 11. & \multicolumn{2}{|c|}{ Оценка общего компонента } & 571 & 275 & 210 & 680 & 602 \\
\hline
\end{tabular}

Оценка общего компонента за весь период анализа находится в области нормальных значений. Следует обратить внимание на падение рентабельности активов и собственного капитала в 2014-2015 годах. Подобная ситуация может объясняться временным лагом между осуществлением капиталовложений и получением экономического эффекта.

Для оценки индивидуального компонента социально-экономической перспективности были отобраны показатели характеризующие деятельность компании по развитию человеческого капитала, социальную ответственность, воздействие на экологию (табл. 4). Все показатели, кроме выбросов загрязняющих веществ, являются позитивными.

Таблицуа 4.

Опорные значения и веса показателей индивидуального компонента

\begin{tabular}{|c|l|c|c|c|c|}
\hline № & \multicolumn{1}{|c|}{ Показатель } & $\begin{array}{c}\text { вес, } \\
\text { доли ед. }\end{array}$ & Хмин & Хнорм & Хмакс \\
\hline 1. & $\begin{array}{l}\text { Расходы на социальные программы для со- } \\
\text { трудников, тыс. руб. на человека }\end{array}$ & 0,1 & 60 & 120 & 240 \\
\hline 2. & $\begin{array}{l}\text { Финансирование благотворительных про- } \\
\text { ектов, культурных и образовательных про- } \\
\text { грамм, поддержка коренных малочислен- } \\
\text { ных народов Севера, \% от прибыли }\end{array}$ & 0,3 & 0,00 & 1,00 & 2,00 \\
\hline
\end{tabular}




\begin{tabular}{|c|l|c|c|c|c|}
\hline 3. & $\begin{array}{l}\text { Повышение квалификации, обучение без- } \\
\text { опасным методом ведения работ в текущем } \\
\text { году, \% сотрудников }\end{array}$ & 0,3 & 10,00 & 40,00 & 70,00 \\
\hline 4. & $\begin{array}{l}\text { Затраты на охрану окружающей среды, \% } \\
\text { от выручки }\end{array}$ & 0,1 & 0,10 & 1,00 & 4,00 \\
\hline 5. & $\begin{array}{l}\text { Удельные выбросы загрязняющих веществ } \\
\text { в атмосферу, тыс. т на млн. условных тонн } \\
\text { добычи углеводородов }\end{array}$ & 0,2 & 1,50 & 2,50 & 8,00 \\
\hline
\end{tabular}

На основе анализа отчетов компании [11] были выделены ключевые принципы политики ПАО «НОВАТЭК» по указанным направлениям.

Руководство компании осознает необходимость соблюдения в своей деятельности концепции устойчивого природопользования. На охрану окружающей среды выделяются значительные финансовые ресурсы. Происходит непрерывное внедрение передовых эколого-ориентированных технологий, реализация мероприятий и проектов, направленных на охрану окружающей среды. Производится оснащение предприятия оборудованием по переработке буровых отходов. Осуществляется реконструкция очистных сооружений и ввод новых очистных объектов. Проводится экологический мониторинг. Большое внимание уделяется вопросам снижения риска аварий.

Компания придерживается принципов соблюдения баланса интересов и несения социальной ответственности. Ключевыми группами стейкхолдеров, в отношении которых проводится активная политика, являются собственники и инвесторы; персонал; потребители; поставщики и партнеры; государство; общество, в том числе коренные народы Севера.

Работа компании с персоналом основана на принципах социального партнерства. Реализуются программы по обучению и развитию персонала. Специалисты компании принимают активное участие в научно-практических конференциях. Проводятся конкурсы профессионального мастерства рабочих профессий.

Компания реализует проекты в области образования, культуры, спорта. Действует комплексная программа поддержки малочисленных северных народов: обустройство поселков, в том числе объектов социально-бытового назначения, образовательных учреждений; 
социальная помощь, содействие развитию здравоохранения; организация культурных мероприятий коренного населения.

Рассчитаем значение индивидуального компонента и интегрального показателя социально-экономической перспективности компании (табл. 5). Для сопоставимости показателей, расходы на социальные программы для сотрудников пересчитаны в ценах 2017 года с применением официальных данных об индексах цен [15]. При расчете интегрального показателя использовался весовой коэффициент 0,6 для общего компонента и 0,4 для индивидуального.

Таблицуа 5.

Оценка показателей индивидуального компонента и интегрального показателя социально-экономической перспективности

\begin{tabular}{|c|c|c|c|c|c|c|c|}
\hline № & \multicolumn{2}{|l|}{ Показатель } & 2013 & 2014 & 2015 & 2016 & 2017 \\
\hline 1. & \multirow{2}{*}{$\begin{array}{l}\text { Расходы на социальные } \\
\text { программы для сотруд- } \\
\text { ников }\end{array}$} & $\begin{array}{c}\text { тыс. руб. на } \\
\text { человека }\end{array}$ & 272,82 & 253,88 & 208,90 & 177,31 & 169,06 \\
\hline 2. & & оценка & 1000 & 1000 & 741 & 478 & 409 \\
\hline 3. & \multirow{2}{*}{$\begin{array}{l}\text { Финансирование благо- } \\
\text { творительных проектов, } \\
\text { культурных и образо- } \\
\text { вательных программ, } \\
\text { поддержка коренных } \\
\text { малочисленных народов } \\
\text { Севера }\end{array}$} & $\begin{array}{l}\text { \% от при- } \\
\text { были } \\
\end{array}$ & 1,09 & 1,90 & 1,35 & 0,72 & 1,68 \\
\hline 4. & & оценка & 91 & 896 & 349 & -283 & 682 \\
\hline 5. & \multirow{2}{*}{$\begin{array}{l}\text { Повышение квалифика- } \\
\text { ции, обучение безопас- } \\
\text { ным методом ведения } \\
\text { работ }\end{array}$} & $\begin{array}{c}\% \text { сотруд- } \\
\text { ников }\end{array}$ & 38,00 & 36,90 & 39,60 & 44,80 & 43,40 \\
\hline 6. & & оценка & -67 & -103 & -13 & 160 & 113 \\
\hline 7. & \multirow{2}{*}{$\begin{array}{l}\text { Затраты на охрану окру- } \\
\text { жающей среды }\end{array}$} & $\begin{array}{c}\% \text { от вы- } \\
\text { ручки }\end{array}$ & 0,12 & 0,18 & 0,16 & 0,22 & 0,35 \\
\hline 8. & & оценка & -976 & -913 & -930 & -863 & -717 \\
\hline 9. & \multirow[t]{2}{*}{$\begin{array}{l}\text { Удельные выбросы за- } \\
\text { грязняющих веществ в } \\
\text { атмосферу }\end{array}$} & $\begin{array}{l}\text { тыс. тонн } \\
\text { на млн. } \\
\text { условных } \\
\text { тонн добы- } \\
\text { чи углево- } \\
\text { дородов } \\
\end{array}$ & 0,45 & 0,77 & 0,87 & 1,52 & 1,45 \\
\hline 10. & & оценка & 1000 & 1000 & 1000 & 984 & 1000 \\
\hline 11. & \multicolumn{2}{|c|}{ Оценка индивидуального компонента } & 210 & 447 & 282 & 121 & 408 \\
\hline 12. & \multicolumn{2}{|c|}{ Интегральная оценка } & 427 & 344 & 239 & 456 & 524 \\
\hline
\end{tabular}


Оценка индивидуального компонента и интегральная оценка социально-экономической перспективности имеют нормальные значения. Выбросы загрязняющих веществ ниже, чем в целом по газодобывающим предприятиям, однако, с учетом работы предприятия в регионе с повышенной экологической уязвимостью, следует активизировать внедрение технологий соответствующих концепции устойчивого развития.

\section{Заключение}

Основные факторы, сдерживающие развитие Северных регионов, связаны с суровым климатом и удаленным географическим положением. Наиболее значимыми из них являются высокие транспортные расходы, дороговизна трудовых ресурсов, уязвимость природной среды.

Основными направлениями нейтрализации негативного воздействия этих факторов являются: использование передовых технологических решений по ресурсосбережению, снижению негативного воздействия на природную среду; реализация концепции устойчивого развития; развитие транспортной и энергетической инфраструктуры; реализация проектов с использованием государственно-частного партнерства.

Перспективные направления развития связаны с природно-ресурсным потенциалом, уникальными условиями для туристко-рекреационной деятельности, в том числе этно-туризма, перспективами стратегического значения Северного морского пути в глобальной логистике.

Для эффективной реализации этих потенциалов необходима взвешенная промышленная, региональная и инновационная политика, реализуемая как на уровне государства, так и на уровне корпораций; активное участие в организациях и проектах международного сотрудничества; нейтрализация негативных сдерживающих факторов, отмеченных выше.

При оценке социально-экономической перспективности предприятий, ведущих хозяйственную деятельность на Крайнем Севе- 
pe, большое значение имеет оценка экологической безопасности, политики по развитию человеческого капитала, инновационной деятельности.

Для добывающих компаний экологическая безопасность и инновационная деятельность тесно взаимосвязаны. Основным направлением снижения негативного воздействия на природу при расширении масштабов хозяйственной деятельности является внедрение новых технологий.

Возможности ведения самостоятельных инновационных разработок в условиях Крайнего Севера ограничены и не всегда целесообразны. Однако компании региона предъявляют высокий платежеспособный спрос на инновации. Данную возможность необходимо использовать для развития инновационной системы страны в целом.

При оценке политики по развитию человеческого капитала целесообразно учитывать как мероприятия направленные на развитие персонала, так и проекты по поддержке населения региона, в том числе коренных малочисленных народов.

\section{Список литературы}

1. Алексеева И.Ю., Аршинов В.И., Чеклецов В.В. «Технолюди» против «Постлюдей»: НБИКС-революция и будущее человека // Вопросы философии. 2013. № 3. С. 12-21.

2. Гулин К.А., Усков В.С. Тренды четвертой промышленной революции // Экономические и социальные перемены: факты, тенденции, прогноз. 2017. Т. 10. № 5. С. 216-221. doi: 10.15838/esc.2017.5.53.15

3. Ендовицкий Д.А., Бабушкин В.А. Анализ капитализации публичной компании и оценка ее инвестиционной привлекательности // Экономический анализ: теория и практика. 2009. №21. С. 2-8.

4. Ендовицкий Д.А., Соболева В.Е. Методические подходы к оценке инвестиционной привлекательности компании-цели слияния/поглощения // Экономический анализ: теория и практика. 2008. №6. С. 2-14.

5. Жуков М.Ю. Методика оценки инвестиционной привлекательности предприятий и групп предприятий // Вестник СибГАУ. 2010. №4. С. 200-204. 
6. Капустина И.В., Переверзева Т.А., Степанова Т.В. Предпосылки институционального регулирования цифровой экономики // Вестник Национальной академии туризма. 2018. № 1. С. 9-11.

7. Кирко В.И., Фаткулина-Яськова Л.М., Захарюта В.В. Оценка технического состояния объектов поселений Эвенкии и Таймыра // Academia. Архитектура и строительство. 2012. №2. С. 115-123.

8. Кондратов Н.А. Опыт разработки стратегий освоения арктического региона зарубежными странами // Арктика: экология и экономика. 2015. №4. С. 78-85.

9. Котляров И. Д. Экосистема: новые способы взаимодействия компании с работниками, клиентами и широкой публикой // Вестник НГУЭУ. 2013. № 4. С. 54-68.

10. Крейнина М. Н. Анализ финансового состояния и инвестиционной привлекательности акционерных обществ в промышленности, строительстве и торговле. М.: ДИС: МВ-Центр, 1994. 256 с.

11. ПАО «НОВАТЭК». URL: http://www.novatek.ru/ru/ (дата обращения 29.05.2018).

12. Плещенко В. И. Закупки в условиях перехода к индустрии 4.0: особенности и перспективы // Логистика сегодня. 2018. № 1. С. 66-72.

13.Савицкая Г.В. Экономический анализ. М.: Новое знание, 2005. $651 \mathrm{c}$.

14. Соколов А. В., Чулок А. А. Долгосрочный прогноз научно-технологического развития России на период до 2030 года: ключевые особенности и первые результаты //Форсайт. 2012. Т.6. №1. С. 12-25.

15. Федеральная служба государственной статистики. URL: http://www. gks.ru. (дата обращения 29.05.2018).

16. Шеремет А.Д. Комплексный анализ хозяйственной деятельности. М.: ИНФРА-М, 2006. 415 с.

17. Шумпетер Й. А. Теория экономического развития. Капитализм, социализм и демократия: пер. с нем. и англ. М.: Эксмо, 2007. 862 с.

18. Яковлева Е.Л., Селиверстова Н.С., Григорьева О.В. Поведенческие факторы проведения технологической модернизации в экономике России // Наука Красноярья. 2017. Том 6. №3. С. 147-163. doi: 10.12731/2070-7568-2017-3-147-163 
19. Albertini E. Does Environmental Management Improve Financial Performance? A Meta-Analytical Review // Organization \& Environment. 2013. No 26. pp. 431-457. doi: 10.1177/1086026613510301

20. Mitchell W.J. Me++: The Cyborg Self and the Networked City. Cambridge, Mass. London: MIT, 2004. 269 p.

21.Porter M.E. Competitive Strategy: Techniques for Analyzing Industries and Competitors. New York: The Free Press, 1998. 397 p.

22. Rifkin J. The Third Industrial Revolution; How Lateral Power is Transforming Energy, the Economy, and the World. London: Palgrave MacMillan, 2011. 270 p.

23. Szalavetz A. The Environmental Impact of Advanced Manufacturing Technologies: Examples from Hungary // Central European Business Review. 2017. vol. 6. No 2. pp. 18-29. doi: 10.18267/j.cebr.177

\section{References}

1. Alekseeva I.Yu., Arshinov V.I., Chekletsov V.V. «Tekhnolyudi» protiv «Postlyudey»: NBIKS-revolyutsiya i budushchee cheloveka [“Technohumans" against "Posthumans": NBICS the revolution and the future of man]. Voprosy filosofii. 2013. № 3, pp. 12-21.

2. Gulin K.A., Uskov V.S. Trendy chetvertoy promyshlennoy revolyutsii [Trends of the Fourth Industrial Revolution]. Ekonomicheskie $i$ sotsial'nye peremeny: fakty, tendentsii, prognoz. 2017. vol. 10. № 5, pp. 216-221. doi: 10.15838/esc.2017.5.53.15

3. Endovitskiy D.A., Babushkin V.A. Analiz kapitalizacii publichnoy kompanii i ocenka yeye investicionnoy privlekatel'nosti [Analysis of capitalization of a public company and evaluation of its investment attractiveness]. Ekonomicheskiy analiz: teoriya i praktika. 2009. №21, pp. 2-8.

4. Endovitskiy D.A., Soboleva V.E. Metodicheskiye podhody k ocenke investicionnoy privlekatel'nosti kompanii-tseli sliyaniya/pogloshcheniya [Methodological approaches to assessing the investment attractiveness of the company-the objectives of the merger / acquisition]. Ekonomicheskiy analiz: teoriya i praktika. 2008. №6, pp. 2-14.

5. Zhukov M.Y. Metodika otsenki investitsionnoy privlekatel'nosti predpriyatiy i grupp predpriyatiy [Technique of an estimation of investment 
appeal of the enterprises and groups of the enterprises]. Vestnik SibGAU. 2010. №4, pp. 200-204.

6. Kapustina I.V., Pereverzeva T.A., Stepanova T.V. Predposylki institutsional'nogo regulirovaniya tsifrovoy ekonomiki [Prerequisites of institutional regulation of the digital economy]. Vestnik Natsional'noy akademii turizma. 2018. № 1, pp. 9-11.

7. Kirko V.I., Fatkulina-YAs'kova L.M., Zaharyuta V.V. Otsenka tekhnicheskogo sostoyaniya ob"ektov poseleniy Evenkii i Taymyra [Estimation of Objects Technical Condition in Evenkia and Tajmyr Settlements]. Academia. Arhitektura i stroitel'stvo. 2012. №2, pp. 115-123.

8. Kondratov N.A. Opyt razrabotki strategiy osvoeniya arkticheskogo regiona zarubezhnymi stranami [Experience of developing the strategy of Arctic development by foreign countries]. Arktika: ekologiya i ekonomika. 2015. №4, pp. 78-85.

9. Kotlyarov I.D. Ekosistema: novye sposoby vzaimodeystviya kompanii s rabotnikami, klientami i shirokoy publikoy [Ecosystem: a new model of company's interaction with employees, customers and public]. Vestnik NGUEU. 2013. № 4, pp. 54-68.

10. Kreynina M.N. Analiz finansovogo sostoyaniya i investitsionnoy pri-vlekatel'nosti aktsionernyh obshchestv v promyshlennosti, stroitel'stve i torgovle [Analysis of financial condition and investment attractiveness of joint-stock companies in industry, construction and trade]. M.: DIS: MV-TSentr, 1994. $256 \mathrm{p}$.

11.PAO «NOVATEK» [PAO «NOVATEK»]. http://www.novatek.ru/en/ (accessed May 29, 2018).

12. Pleshchenko V.I. Zakupki v usloviyakh perekhoda k industrii 4.0: osobennosti i perspektivy [Procurement in the transition to industry 4.0: features and prospects]. Logistika segodnya. 2018. № 1, pp. 66-72.

13. Savitskaya G.V. Ekonomicheskiy analiz [Economic analysis]. M.: Novoe znanie, 2005. $651 \mathrm{p}$.

14. Sokolov A., Chulok A. Dolgosrochnyy prognoz nauchno-tekhnologicheskogo razvitiya Rossii na period do 2030 goda: klyuchevye osobennosti i pervye rezul'taty [Russian Science and Technology Foresight - 2030: Key Features and First Results]. Foresight-Russia. 2012. vol. 6. № 1, pp. 12-25. 
15.Federal'naya sluzhba gosudarstvennoy statistiki [Federal Service of State Statistics]. http://www.gks.ru. (accessed May 29, 2018).

16. Sheremet A.D. Kompleksnyy analiz hozyaystvennoy deyatel'nosti [Complex analysis of economic activity]. M.: INFRA-M, 2006. 415 p.

17. Shumpeter J.A. Teoriya ekonomicheskogo razvitiya. Kapitalizm, sotsializm i demokratiya [Theory of economic development. Capitalism, socialism and democracy]: translation from German and English. M.: Eksmo, 2007. 862 p.

18. Iakovleva E.L., Seliverstova N.S., Grigoreva O.V. Povedencheskiye faktory provedeniya tehnologicheskoy modernizatsii v ekonomike Rossii [Behavioral factors of technological modernization in the Russian economy]. Nauka Krasnoyar'ya. 2017. V. 6, №3, pp. 147-163. doi: 10.12731/2070-7568-2017-3-147-163

19. Albertini E. Does Environmental Management Improve Financial Performance? A Meta-Analytical Review. Organization \& Environment. 2013. No 26, pp. 431-457. doi: 10.1177/1086026613510301

20. Mitchell W.J. Me++: The Cyborg Self and the Networked City. Cambridge, Mass. London: MIT, 2004. 269 p.

21. Porter M.E. Competitive Strategy: Techniques for Analyzing Industries and Competitors. New York: The Free Press, 1998. 397 p.

22. Rifkin J. The Third Industrial Revolution; How Lateral Power is Transforming Energy, the Economy, and the World. London: Palgrave MacMillan, 2011. 270 p.

23. Szalavetz A. The Environmental Impact of Advanced Manufacturing Technologies: Examples from Hungary. Central European Business Review. 2017. vol. 6. No 2. pp. 18-29. doi: 10.18267/j.cebr.177

\section{ДАННЫЕ ОБ АВТОРАХ}

Жуков Максим Юрьевич, ассистент кафедры «Экономики и управления в строительном комплексе» Сибирский федеральный университет пр. Свободный, 79, г. Красноярск, Красноярский край, 660041, Российская Федерация mzhukov@sfu-kras.ru 
Глоба Светлана Борисовна, доцент кафедры «Экономики и управления в строительном комплексе», кандидат экономических наук

Сибирский федеральный университет

пр. Свободный, 79, г. Красноярск, Красноярский край, 660041, Российская Федерация

SGloba@sfu-kras.ru

\section{DATA ABOUT THE AUTHORS}

Zhukov Maksim Yur'evich, Assistant of the Department «Economy and Management in the Construction Complex»

Siberian Federal University

79, Svobodny pr., Krasnoyarsk, Krasnoyarsk region, 660041, Russian Federation

mzhukov@sfu-kras.ru

SPIN-code: 8565-2313

ORCID: 0000-0002-1726-4307

Globa Svetlana Borisovna, Associate Professor of the Department «Economy and Management in the Construction Complex», Candidate of Economic Sciences

Siberian Federal University

79, Svobodny pr., Krasnoyarsk, Krasnoyarsk region, 660041, Russian Federation

SGloba@sfu-kras.ru

SPIN-code: 4207-9213

ORCID: 0000-0003-1664-0275

ResearcherID: K-9581-2018 